\title{
DEVELOPMENT OF TECHNOLOGY OF MECHANIZED ARC WELDING IN REPAIR OF PRESSURIZED MAIN GAS PIPELINE*
}

\author{
O.I. OLEJNIK, S.Yu. MAKSIMOV, A.P. PALTSEVICH and E.I. GONCHARENKO \\ E.O. Paton Electric Welding Institute, NASU \\ 11 Kazimir Malevich Str., 03680, Kiev, Ukraine. E-mail: office@paton.kiev.ua
}

\begin{abstract}
Complex of investigations was carried out on development of a technology of mechanized gas-shielded arc welding applicable to repair of main gas pipelines by reinforcing structures. Determined are the conditions for prevention of pore formation in welded joints due to break of gas shield under effect of wild blast. The tests were made with weld metal of the butt and lap-butt joints, welded using modern flux-cored wires and solid wire Sv-08G2S. Effect of butt joint welding practice on mechanical properties and impact toughness of the weld metal is shown. Influence of factors, determining a risk of cold crack formation in welded joints from X70 strength class low-alloy steel, is investigated. It is determined that Sv-08G2S, E71T-1 and DW-A55 welding wires correspond to the requirements on providing a necessary level of mechanical characteristics and impact toughness of weld metal, content of diffusion hydrogen in deposited metal and can be recommended for further technology approval under conditions of field repair of in-service pipelines. Main recommendations on the welding practice of butt and lap-butt welded joints and approximate modes of welding in different spatial positions are stated. 19 Ref., 6 Tables, 7 Figures.
\end{abstract}

Keywords : main gas pipeline, arc welding, welded joints, flux-cored wire, cold cracks, pre-heating, diffusion hydrogen

It is known fact that mechanized gas-shielded arc welding results in a rise of efficiency of welding works in comparison with manual welding. Systems for mechanized arc welding over pipelines, developed by leading world companies (ESAB, Lincoln Electric, CRC) have been already used at least for 40 years. However, all these developments are related to the conditions of welding during main gas pipelines (MGP) construction. Experience of mechanization of repair welding works on pressurized main pipelines under field conditions is extremely limited.

Technologies providing for application of manual arc welding are currently used in Ukraine during repair of pressurized MGP. On the one hand, it is related with welding process simplicity, its accessibility under field repair conditions, wide spectrum of available welding consumables and equipment. At the same time, manual method of welding is regulated by different reference documents which are used for work performance on MGP, including one under pressure. The main disadvantage is a relatively low speed of welding, that effects repair process duration. For example, it can be mentioned that welding of only one circumferential joint on $1420 \mathrm{~mm}$ diameter pipeline takes more than $5 \mathrm{~h}$ for two welders. Taking into account that this sort of repair requires decrease of pressure in the main pipeline, such a possibility, on different reasons under conditions of gas transit by the territory of Ukraine, can appear only at nighttime, when gas consumption volumes being reduced. Therefore, a risk of defects in welded joints due to insufficient visibility increases.

Thus, it is a need to intensify the welding-repair works with simultaneous rise of their quality and safety. One of ways out from such a situation is application of technology of mechanized gas-shielded arc welding using novel welding consumables.

Selection of welding consumables for mechanized arc welding. Currently, solid wires and fluxcored wires, which correspond to the requirements [1-5], are provided for application with mechanized gas-shielded arc welding at MGP construction and repair.

The following welding consumables, namely solid wire Sv-08G2S (Ukraine) and flux-cored wires DW-50, DW-A55 (Kobelco, Japan), E71T-1 (Baoding lanyu welding material, PRC) and PPs-TMB7 (TM. WELTEC, Ukraine), were selected for working out a technology of mechanized gas-shielded arc welding in all spatial positions (overhead, vertical, horizontal on vertical surface, flat). Such a choice is based on the need to compare welding-technological

\footnotetext{
${ }^{*}$ Based on materials of the work performed under purpose-oriented integrated program of the NAS of Ukraine «Problems of residual life and safe operation of structures, constructions and machines» (2013-2015).
} 
characteristics of new, modern high-quality flux-cored wires with experience of wide industrial application of well-known cheaper wire Sv-08G2S. It is done for determination of possibility of their further application under conditions of repair of pressurized MGP. All the wires were of the same diameter $1.2 \mathrm{~mm}$.

Effect of wind speed on quality of butt welds formation. In welding performance one of the factors, effecting welded joint quality, is reliability of shield of a weld metal molten by arc from air. This factor becomes critical for mechanized arc welding under field conditions, due to expected detrimental effect of wild gusts on arc gas shield. Therefore, there is a necessity in excperimental determination of effect of wind speed on efficiency of shielding of welding zone, and, respectively, quality of butt joints formation depending on shielding gas consumption. Welding wires Sv-08G2S and E71T-1, and shielding gas $\mathrm{CO}_{2}$ were used for investigations.

Limit values of shielding gas consumption $Q_{\mathrm{g}}$, which allows prevention of pores at set air movement speed, were experimentally received at the first stage. It is determined that solid wire Sv-08G2S eliminates appearance of pores at wind speed up to $v_{\text {wind }}=2 \mathrm{~m} / \mathrm{s}$ in $\mathrm{CO}_{2}$ welding under field conditions, as well as it is shown that application of flux-cored wire increases allowable wind speed to $2.6 \mathrm{~m} / \mathrm{s}$ due to presence of gas-slag shield from core components. Such a result is achieved at rise of gas consumption from 10-15 ( $v_{\text {wind }}=0-0.25 \mathrm{~m} / \mathrm{s}$ ) to $301 / \mathrm{min}$.

It is known fact that nitrogen and oxygen are impurities in low-alloy steels [6, 7]. Therefore, the second stage was dedicated to the experiments on determination of effect of wind speed on content of these elements in the weld metal. Specimens Mi99 for gas analysis were manufactured from metal deposited at different $v_{\text {wind }}$ values. The investigations were carried out using gas analyzer LECO TC 436 . The results are given in Table 1.

It can be seen that consumption of shielding gas in the amount necessary for maximum allowable $v_{\text {wind }}$ values provides for insignificant rise of nitrogen and oxygen content in the weld metal. According to absolute value received nitrogen content is 3-3.5 times less than maximum recommended $(0.02 \%)$ one for mechanized $\mathrm{CO}_{2}$ welding. Total content of oxygen in the weld, made by solid wire, is less of that was received for Sv-08G2S earlier (0.0573\%) in work [8]. As for flux-cored wire it should be noted that some rise of oxygen in the weld metal is related with its presence in the core, but in absolute determination the oxygen content is on the level of reference values for wires with rutile type core $([\mathrm{O}]=0.060-0.085 \%)$ [9].
Table 1. Content of nitrogen and oxygen in deposited metal for different welding consumables

\begin{tabular}{|c|c|c|c|c|}
\hline \multirow{2}{*}{ Wire } & $Q_{\mathrm{g}}, 1 / \mathrm{min}$ & {$[\mathrm{N}], \%$} & {$[\mathrm{O}], \%$} & $v_{\text {wind }}, \mathrm{m} / \mathrm{s}$ \\
\hline \multirow{2}{*}{ Sv-08G2S } & 10 & 0.0065 & 0.045 & 0.0 \\
\cline { 2 - 5 } & 27 & 0.0068 & 0.045 & 2.0 \\
\hline \multirow{2}{*}{ E71T-1 } & 10 & 0.0054 & 0.056 & 0.0 \\
\cline { 2 - 5 } & 30 & 0.0058 & 0.062 & 2.5 \\
\hline
\end{tabular}

Mechanical properties of metal of butt and lapbutt welds. Bandages and pipe sleeves of different structure are used in repair of MGP damages sections. They provide for strengthening of pipe wall as well as preserve working efficiency of the main pipe at integrity damage of the wall in place of the defect under sleeve. Longitudinal butt and circumferential lap-butt welds are used for joining separate cylinder elements between themselves as well as with pipeline.

Reference documents [10] require that the welding consumables used for MGP with outer diameter to $1420 \mathrm{~mm}$, made from steels of strength class up to K60 included and operating under working pressure up to $8.3 \mathrm{MPa}$, correspond to the following requirements:

1) ultimate tensile strength at static tension testing should be not lower than reference value of that of the pipe base metal;

2) weld metal hardness should be not more than HV10-280, HAZ - not more than HV10-300 for pipes of strength class up to K55 included, and not more than $H V 10-325$ for pipes of strength class more than K55 till K60 included;

3) Charpy impact toughness of weld metal should be not less than $34 \mathrm{~J} / \mathrm{cm}^{2}$ at temperature $20{ }^{\circ} \mathrm{C}$ lower than minimum temperature of wall of in-service gas pipeline (in Ukraine such a temperature for buried gas pipelines should be $0{ }^{\circ} \mathrm{C}$ ).

Butt joints of $16 \mathrm{~mm}$ thickness with groove preparation of total angle $60^{\circ}$ were welded for determination of welded joint mechanical properties. Each layer

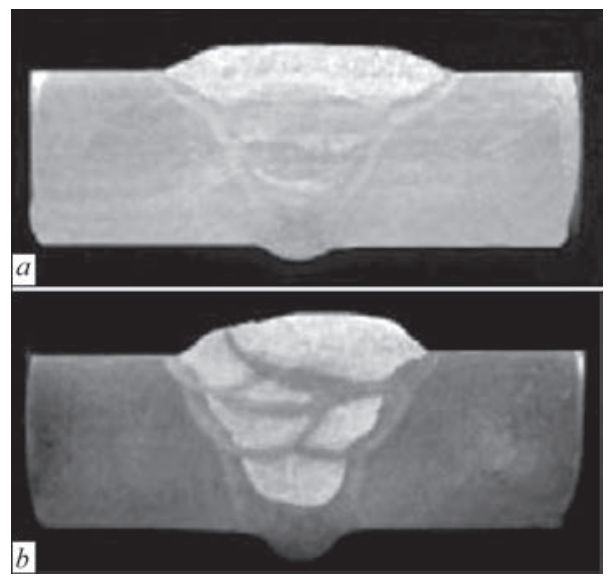

Figure 1. Macrosection of butt welded joint: $a$ - welding «one layer per one pass»; $b$ - welding by stringer bead 
Table 2. Mechanical characteristics of weld metal

\begin{tabular}{|c|c|c|c|c|c|c|c|}
\hline \multirow{2}{*}{ Wire, shielding gas } & \multirow{2}{*}{$\sigma_{y}, \mathrm{MPa}$} & \multirow{2}{*}{$\sigma_{t}, \mathrm{MPa}$} & \multirow{2}{*}{$\delta_{5}, \%$} & \multirow{2}{*}{$\psi, \%$} & \multicolumn{3}{|c|}{$K V C, \mathrm{~J} / \mathrm{cm}^{2}$, at $T,{ }^{\circ} \mathrm{C}$} \\
\hline & & & & & 0 & -20 & -40 \\
\hline $\mathrm{Sv}-08 \mathrm{G} 2 \mathrm{~S}, \mathrm{CO}_{2}$ & 423 & 552 & 27.4 & 72.1 & $(168-138) / 153$ & $(91-88) / 89$ & $(71-62) / 67$ \\
\hline $\mathrm{Sv}-08 \mathrm{G} 2 \mathrm{~S}, \mathrm{Ar}+\mathrm{CO}_{2}$ & 430 & 561 & 30.9 & 75.1 & $(177-154) / 165$ & $(98-93) / 95$ & $(75-71) / 72$ \\
\hline E7IT-1, $\mathrm{Ar}+\mathrm{CO}_{2}$ & 444 & 557 & 29.0 & 71.6 & $(151-107) / 128$ & $(55-53) / 53$ & $(63-32) / 46$ \\
\hline $\mathrm{DW}-\mathrm{A} 55, \mathrm{Ar}+\mathrm{CO}_{2}$ & 484 & 589 & 27.3 & 71.0 & $(176-152) / 164$ & $(147-128) / 136$ & $(49-45) / 46$ \\
\hline DW-50, $\mathrm{CO}_{2}$ & 468 & 567 & 29.1 & 72.8 & $(44-40) / 41$ & $(23-22) / 22$ & $(14-13) / 13$ \\
\hline PPs-TMV7, $\mathrm{CO}_{2}$ & 476 & 570 & 29.0 & 71.6 & $(172-170) / 170$ & $(125-110) / 117$ & $(86-80) / 83$ \\
\hline
\end{tabular}

Table 3. Average hardness $H V 10$ of weld metal and HAZ

\begin{tabular}{|c|c|c|c|c|c|c|}
\hline \multirow{2}{*}{ Area of examination } & \multicolumn{6}{|c|}{ Wire, shielding gas } \\
\hline & $\mathrm{Sv}-08 \mathrm{G} 2 \mathrm{~S}, \mathrm{CO}_{2}$ & $\mathrm{~Sv}-08 \mathrm{G} 2 \mathrm{~S}, \mathrm{Ar}+\mathrm{CO}_{2}$ & E7IT- $1, \mathrm{Ar}+\mathrm{CO}_{2}$ & DW-A55, $\mathrm{Ar}+\mathrm{CO}_{2}$ & DW-50, $\mathrm{CO}_{2}$ & PPs-TMV7, $\mathrm{CO}_{2}$ \\
\hline Weld metal & 149 & 148 & 148 & 153 & 149 & 148 \\
\hline HAZ & 162 & 160 & 154 & 158 & 165 & 155 \\
\hline
\end{tabular}

was made per one pass (Figure 1, $a$ ). The material was pipe steel X70 with $\sigma_{\mathrm{y}}>480 \mathrm{MPa}, \sigma_{\mathrm{t}}>560 \mathrm{MPa}$, $\delta_{5}>18 \%$, which was used in Ukraine in 1980s during construction of gas pipeline «Urengoj-Pomary-Uzhgorod».

Welding was carried out using combined technology [10], i.e. root weld of butt joint was performed manually using stick electrode UONI $13 / 45$ of $3 \mathrm{~mm}$ diameter, the groove was filled by wires. $\mathrm{CO}_{2}$ and mixture of $\mathrm{Ar}+18 \% \mathrm{CO}_{2}$ were applied as shielding gases. There were following modes of welding: for Sv-08G2S wire $-I_{\mathrm{w}}=140-150 \mathrm{~A}, U=20-21 \mathrm{~V}$; for flux-cored wires $-I_{\mathrm{w}}=200-220 \mathrm{~A}, U=25-27 \mathrm{~V}$. Welding speed $v_{\mathrm{w}}=0.2-0.25 \mathrm{~m} / \mathrm{min}, Q_{\mathrm{g}}=15 \mathrm{l} / \mathrm{min}$. Specimens for determination of weld metal mechanical characteristics Mi12 type 2 and impact toughness Mi50 type 11 were cut out according to the requirements of $[3,5]$. The results of tests are given in Table 2 .

Analysis of received data and their comparison showed that from point of view of fulfillment of the first condition wires E7IT-1, DW-50, PPs-TMV76 and Sv-08G2S can be used in welding of steel of K55 strength class, and flux-cored wire DW-A55 for pipes of K60 (X70) strength class. Measurement of metal hardness in the weld center and HAZ showed that all wire grades correspond to the second requirement (Table 3).

In regard to impact toughness indices $(\mathrm{KCV})$ it was determined that flux-cored wire DW-50 doesn't correspond to the third requirement for -20 and $-40{ }^{\circ} \mathrm{C}$ testing temperatures (see Table 2). It is suggested that one of the reasons of low $\mathrm{KCV}$ indices is related with welding practice, namely weaving technique with high specific heat input indices [11] was used for groove filling.

Therefore, it is decided to change a scheme of groove filling and use, one in which butt welding is carried out by stringer beads without weaving (Figure $1, b)$ with moderate heat input. $\mathrm{CO}_{2}$ was used as shielding gas. Test results of specimens of weld metal being welded using new scheme showed significant rise of mechanical characteristics and impact toughness: $\sigma_{y}=540 \mathrm{MPa} ; \sigma_{t}=612 \mathrm{MPa} ; \delta_{5}=27 \%$; $\psi=71.5 \% ; K C V_{0}=(217-172) / 197, K C V_{-20}=(160$ $101) / 125, K_{-40}=(87-51) / 70 \mathrm{~J} / \mathrm{cm}^{2}$.

Comparison of these results with preliminary received ones show that increase of mechanical characteristics and impact toughness of welded joint metal requires change of the preliminary selected practice of butt welding for one providing groove filling by stringer beads without oscillations. Such a conclusion was verified in evaluation of impact toughness of the
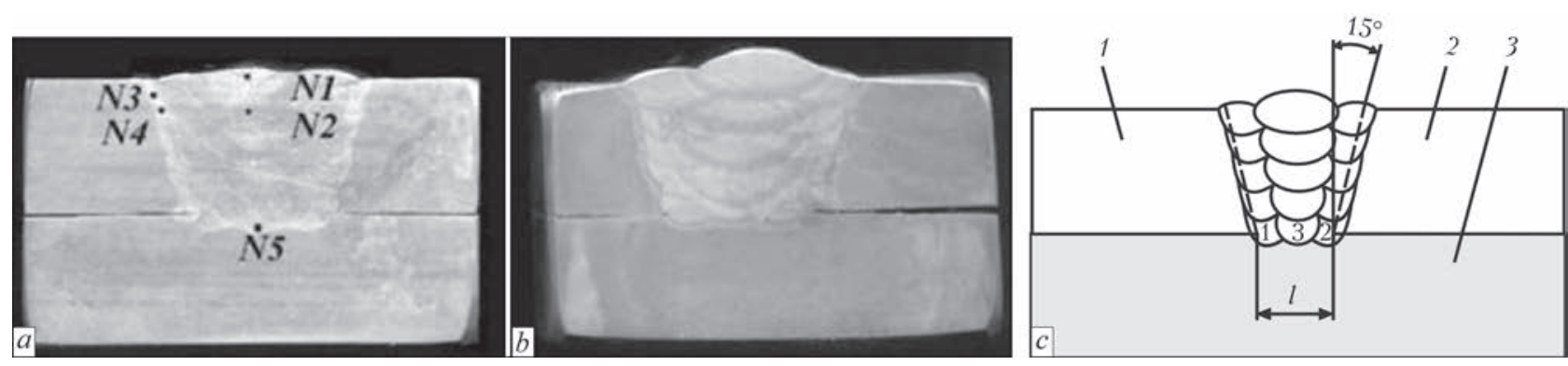

Figure 2. Macrosection of lap-butt welded joint made with wire Sv-08G2S ( $a$ ) and PPs-TMV7 $(b)$, and scheme of groove preparation and welding $(c): 1$ - sleeve; 2 - technological ring; 3 - gas pipeline wall; $l$ - gap between pipe sleeve elements 
Table 4. Impact toughness of metal of lap-butt welds

\begin{tabular}{|c|c|c|c|}
\hline \multirow{2}{*}{ Wire, shielding gas } & \multicolumn{3}{|c|}{$K V C, \mathrm{~J} / \mathrm{cm}^{2}$, at $T,{ }^{\circ} \mathrm{C}$} \\
\cline { 2 - 4 } & 0 & -20 & -40 \\
\hline Sv-08G2S, $\mathrm{CO}_{2}$ & $(164-148) / 155$ & $(171-125) 142$ & $(100-65) / 81$ \\
\hline PPs-TMV7, $\mathrm{CO}_{2}$ & $(176-153) / 165$ & $(160-127) / 140$ & $(127-105) / 118$ \\
\hline
\end{tabular}

lap-butt joints, in which every layer was carried out by inside separate beads 1,2 on every edge, after what bead 3 was deposited (Figure 2,c). Wires PPs-TMV7 and $\mathrm{Sv}-08 \mathrm{G} 2 \mathrm{~S}$ were used for welding.

Table 4 provides for the results of Mi50 specimen testing. Analysis of data showed that high impact toughness level, which significantly exceeds minimum necessary level of this index - not less than $34 \mathrm{~J} / \mathrm{cm}^{2}$, is preserved for all range of testing temperature.

The following sections were taken for metallographic examinations: $N 1$ - weld metal of the last layer; N2 - HAZ in the weld metal; N3 - zone of coarse grain of the last layer; $N 4$ - zone of coarse grain with structural changes after performance of the following layer; N5 - zone of coarse grain in weld root (Figure 2,a).

Examination of joint specimens showed that parts $N 1$ and $N 2$ have ferrite-pearlite structure at dominance of ferrite phase. Hardness makes HV1-1650 $1750 \mathrm{MPa}$. Metal structure in $N 2$ as a result of heat effect is fine ferrite-pearlite with mesh 10 grain. In HAZ metal (N3 and N4) the structure is ferrite-pearlite with 1970-2130 MPa hardness. Increase of hardness up to $2360-2640 \mathrm{MPa}$ is observed in N5 part due to accelerated cooling. It is determine that welding by separate beads allows receiving fine, virtually uniform on joint height ferrite-pearlite structure, and this promotes for solution of a problem of acquiring increased values of impact toughness in welds in comparison with minimum necessary one.

Evaluation of welded joint resistance to cold crack formation. One of the factors in risk of cold crack appearance is a stress-strain state of the welded joint $[12,13]$. «Patch-sleeve» or «patch-sleeve with soil» structures [14] are used in repair of pipes with local corrosion defects. The peculiarity of these structures is presence of circumferential lap-butt weld which joins $100-120 \mathrm{~mm}$ diameter pitch with sleeve and pipe along the contour. High level of stresses as a result of metal shrinkage and rigid fixing is observed in a multi-layer weld at such technical solution. There is a risk of appearance of cold cracks in combination with other factors (diffusion hydrogen, microstructure).

Tests using Marine sample $[15,16]$ were carried out for determination of the conditions effecting re- sistance to cold cracks formation in «patch-sleeve» lap-butt joint. Such a technological sample (Figure 3) simulates a real weld in full measure, and corresponding relationship of disk diameter to plate width can develop a level of stresses close to steel yield strength.

Parts of two samples were manufactured from $1420 \mathrm{~mm}$ diameter pipe segments. $\mathrm{CO}_{2}$ welding using flux-cored wire PPs-TMV7 was carried out according to indicated scheme. Welding mode was $I_{\mathrm{w}}=190$ $200 \mathrm{~A}, U_{\mathrm{a}}=26-27 \mathrm{~V}, v_{\mathrm{w} . \mathrm{f}}=9.1 \mathrm{~m} / \mathrm{min}$. Two microsections from each quadrant were cut out for crack visual detection. It was expected that the largest level of stresses would be developed in quadrant $I V$, where, respectively, the crack being expected [17].

Examination of sample microsection, which was not subjected to pre-heating, showed that deposition of the next bead after cooling of the previous one to $20{ }^{\circ} \mathrm{C}$ resulted in formation of cold crack in quadrant IV (Figure 4, a). Preliminary and concurrent heating to $160-180{ }^{\circ} \mathrm{C}$ allowed eliminating its appearance (Figure $4, b$ ).

It is determined that in the first case the crack appeared in the root part at fusion line from circumferential weld face. The crack is nucleated in a stress raiser, namely zone of transfer of surfaces of sample lap elements in the weld metal. Radial stresses from

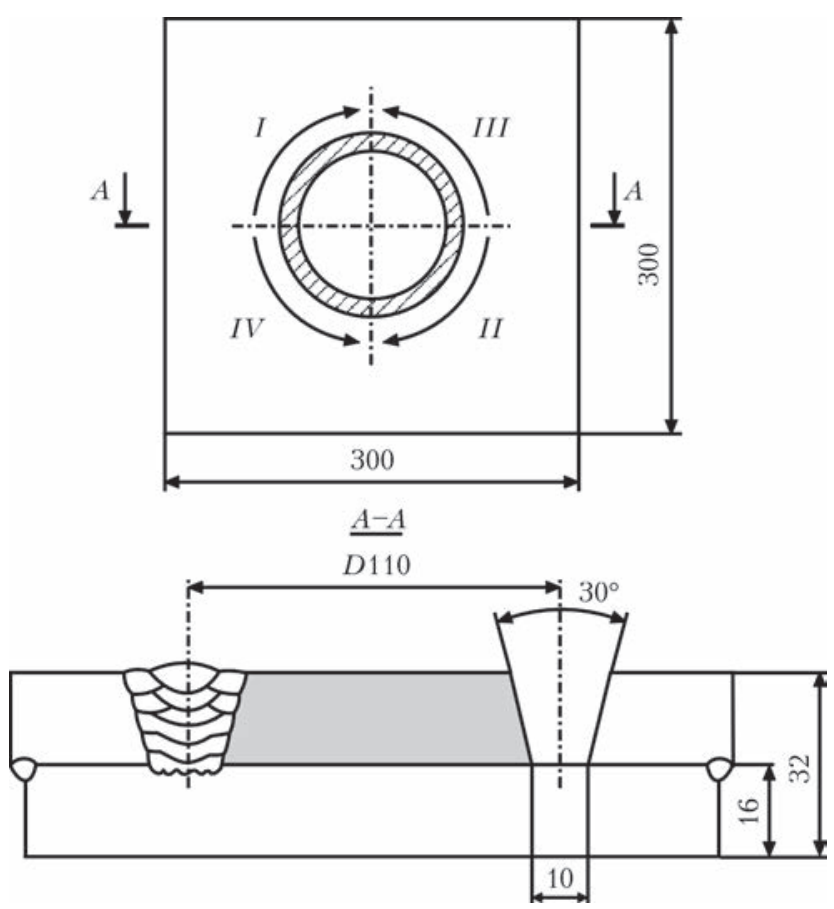

Figure 3. Scheme of Marine technological specimen with sequence of lap-butt weld 

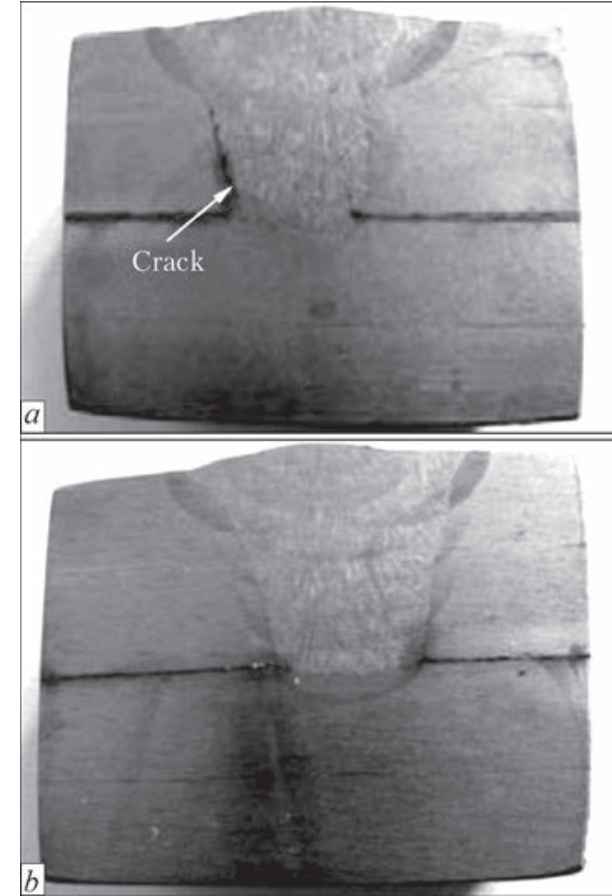

Figure 4. Macrosection of Marine specimen in mechanized welding: $a$ - without pre-heating; $b$ - with pre-heating and concurrent heating to $160-180^{\circ} \mathrm{C}$

metal shrinkage, being higher from the weld face than that acting from the inner side [18], are the reason of this defect. In this relation, pre-heating to $160-180^{\circ} \mathrm{C}$ with keeping such a temperature before performance of each next pass is reasonable to be used for prevention of cold crack formation in the multi-layer welds, as well as quality welding consumables are to be applied having $\delta_{5}>20 \%$ elasticity level at $-20{ }^{\circ} \mathrm{C}$ and providing content of diffusion hydrogen in the deposited metal of not more than $10 \mathrm{~cm}^{3} / 100 \mathrm{~g}$. Diameter of patch shall be additionally increased up to $200 \mathrm{~mm}$ for reduction of stress level.

Another factor, having significant effect on risk of cold crack appearance during mechanized arc weld-

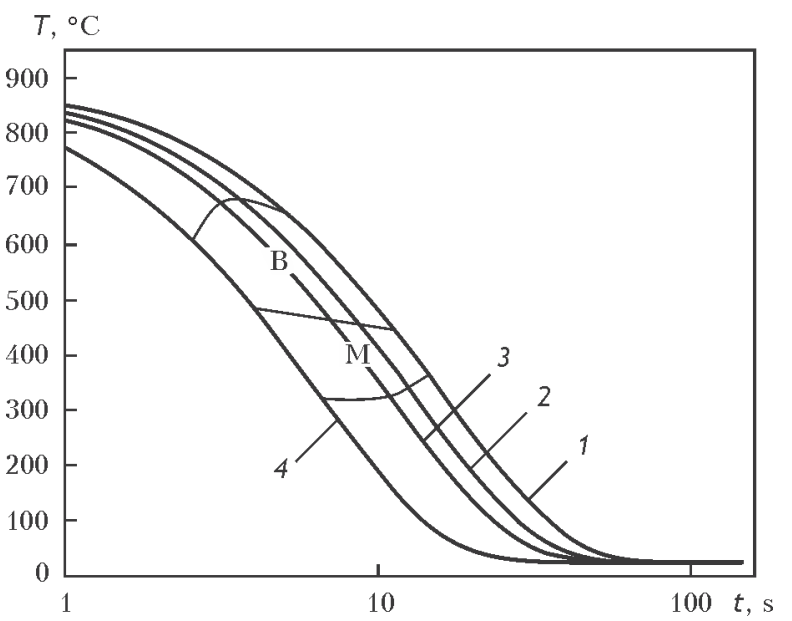

Figure 5. Austenite CCT diagram in HAZ metal of steel X70 at different cooling rates in $800-500{ }^{\circ} \mathrm{C}$ range: $1-40(8.6 \% \mathrm{M})$; $2-50(20.4 \% \mathrm{M}) ; 3-60(23 \% \mathrm{M}) ; 4-90{ }^{\circ} \mathrm{C} / \mathrm{s}(67 \% \mathrm{M})$ ing on in-service MGP, is microstructure of HAZ metal. The information on time of weld and HAZ metal staying in $800-500{ }^{\circ} \mathrm{C}$ temperature interval at intensive heat sink was received in experimental-calculation way. It shows that cooling rate in welding without pre-heating makes $45-60{ }^{\circ} \mathrm{C} / \mathrm{s}$, and that at $150{ }^{\circ} \mathrm{C}$ pre-heating is $30-40{ }^{\circ} \mathrm{C} / \mathrm{s}$. Due to the fact that most pipe steel grades have tendency to formation of hardening structures under indicated conditions, the investigations were carried out on effect of metal cooling rate on structure of HAZ metal of X70 steel.

The investigations were carried out with the help of Gleeble 3800 complex. Special specimens were used for simulation of welding thermal cycles in HAZ metal overheating area, in which cooling rate for $800-500{ }^{\circ} \mathrm{C}$ temperature interval made $40,50,60$ and $90{ }^{\circ} \mathrm{C} / \mathrm{s}$. Received austenite CCT diagram (Figure 5) and its analysis showed the following.

Amount of martensite phase increases from 8.6 to $23 \%$ in steel X70 at cooling rate interval $40-60{ }^{\circ} \mathrm{C} / \mathrm{s}$ and it is significantly less than $50 \%$ value, at which it is assumed that this steel is subjected to cold crack formation. Increase of cooling rate to $90{ }^{\circ} \mathrm{C} / \mathrm{s}$, typical for conditions of wet underwater welding, rises amount of martensite in HAZ metal to 65-68 \%, which is dangerous for welded joint working capacity.

Metallographic examinations of the specimens showed that integral hardness in HAZ metal lies in $H V 10-270-300$ range for $40-60{ }^{\circ} \mathrm{C} / \mathrm{s}$ cooling rate. It does not exceed the limit HV10-325 for steels of X70 strength class, and application of pre-heating to $150{ }^{\circ} \mathrm{C}$ has positive effect on morphology of HAZ metal microstructure. Reliable results, received with the help of Gleeble complex, allow making a conclusion on necessary continuation of investigations of long-term operated pipe steel of X52, X56, X60, X65 strength class applicable to MGP repair conditions.

It is known fact that diffusion hydrogen has significant effect on risk of cold crack appearance in welded joints, and one of its sources is electrode metal. Reference documents regulate application of welding consumables providing content of diffusion hydrogen in the deposited metal of not more than $10 \mathrm{~cm}^{3} / 100 \mathrm{~g}$. In this connection examinations on determination of diffusion hydrogen in the deposed metal using chromatographic method [19] were carried out for all welding wires. Before experiments the flux-cored wires were dried in a furnace at $200-250{ }^{\circ} \mathrm{C}$ for not less than $3 \mathrm{~h}$ for moisture removal. Metal deposition on special specimens (three pieces for each wire grade) was carried out in $\mathrm{Ar}+\mathrm{CO}_{2}$ mixture using welding tractor TS-17 on modes providing heat input at $5.8-6.5 \mathrm{~kJ} / \mathrm{cm}$ level. Average content of diffusion hydrogen in the deposited metal for each wire grade is the following: $[\mathrm{H}]_{\text {dif.d.m }}=3.4-3.6$ for 

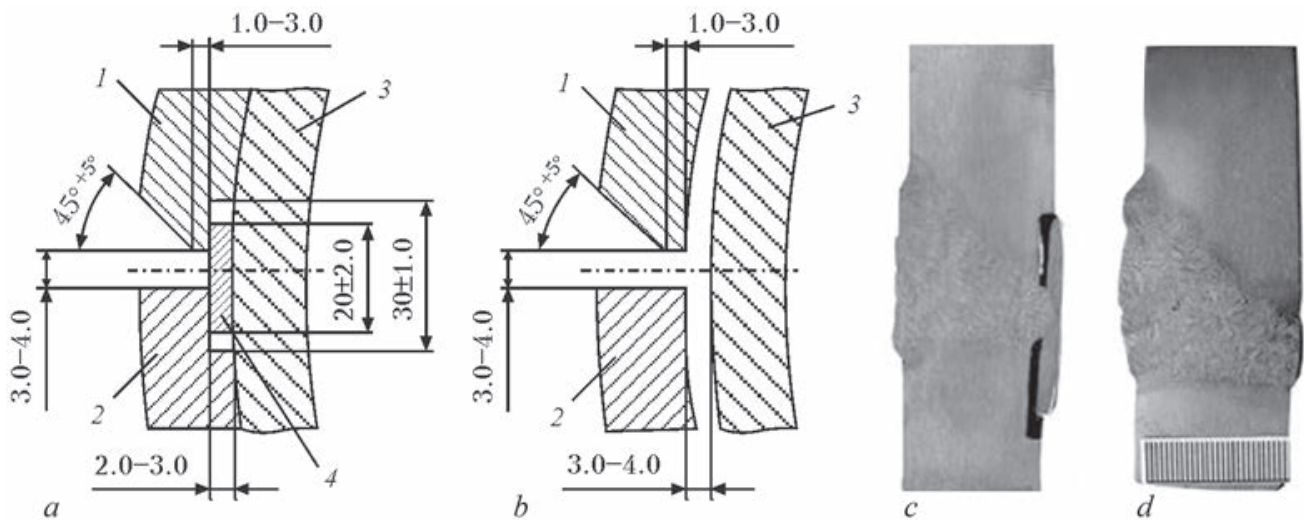

Figure 6. Longitudinal butt joints of strengthening structural elements: $a$ - groove preparation for welding with backing; $b$ - for welding without backing; $c$ - macrosection of joint with backing plate (wire DW-A55); $d$ - of joint made by Sv-08G2S wire without baking; 1,2 - wall of upper and lower strengthening element, respectively; 3 - gas pipeline wall; 4 - backing plate

Table 5. Recommended modes of welding of butt joint with DW-A55 and Sv-08G2S* wire in mixture of Ar $+18 \% \mathrm{CO}_{2}$

\begin{tabular}{|c|c|c|c|}
\hline \multirow{2}{*}{ Parameter } & \multicolumn{3}{|c|}{ Groove fill pass } \\
\cline { 2 - 4 } & Root & Filling & $(7.4-7.7) /(3.6-3.8)$ \\
\hline Wire feed rate, $\mathrm{m} / \mathrm{min}$ & $(9.0-9.2) /(3.6-3.8)$ & $(9.0-9.2) /(4.0-4.1)$ & $(180-190) /(125-130)$ \\
\hline Welding current, A & $(200-210) /(125-130)$ & $(205-215) /(145-155)$ & $(25.0-26.0) /(18.0-18.5)$ \\
\hline Arc voltage, V & $(26.0-26.3) /(18.0-18.5)$ & $(26.5-27.0) /(19.0-20.0)$ & $(10-14) /(10-14)$ \\
\hline Wire extension, mm & $(20-23) /(18-23)$ & $(16-20) /(16-20)$ & \\
\hline "Nominator - for wire DW-A55, denominator - Sv-08G2S.
\end{tabular}

Sv-08G2S; 12.0-13.2 for DW-50; 7.6-8.5 for DWA55; 9.7-10.0 for E71T-1; $10.1-11.8 \mathrm{~cm}^{3} / 100 \mathrm{~g}$ for PPs-TMV7 wire.

It can be seen that the lowest content of diffusion hydrogen in the deposited metal is observed in application of simple solid wire Sv-08G2S, and that corresponds to welding consumables providing its very low level up to $5 \mathrm{~cm}^{3} / 100 \mathrm{~g}$. Flux-cored wires DWA55 and E7IT-1 correspond to welding consumables which provide for low level of diffusion hydrogen up to $10 \mathrm{~cm}^{3} / 100 \mathrm{~g}$. Two more wires (DW-50 and PPsTMV7) exceed allowable limit $[\mathrm{H}]_{\text {dif.d.m }}=10 \mathrm{~cm}^{3} / 100 \mathrm{~g}$ and currently can not be recommended for application for MGP repair conditions.

Development of technology for welding of reinforcing structural elements. The main attention in development of technology of mechanized gas-shielded arc welding of reinforcing elements was given to butt and lap-butt joints in different spatial positions. At that, it was an attempt to determine such welding modes, which, on the one hand, would provide quality formation of multilayer welds and, on the other hand, do not require significant correction in change of spatial position.

Welding of longitudinal butt joints in horizontal position over vertical plane (Figure $6, a, b$ ) were carried out by DW-A55 and Sv-08G2S wires in $\mathrm{Ar}+\mathrm{CO}_{2}$ mixtures. The material is a segment of $1420 \mathrm{~mm}$ diameter X70 pipe with $16 \mathrm{~mm}$ pipe wall.

Flux-cored wire was used for welding variant with backing plate (Figure 6,c), and Sv-08G2S wire was applied for welding without backing (Figure 6, d). Welding practice provided deposition of separate pass by stringer beads with small weaving. Root pass was made by backward inclined torch. The second and all other filling passes were carried out without transverse oscillations by stringer beads with foreward inclined torch, correcting amount of passes in each layer depending on width of groove. Facing layer was carried out by separate passes with small transverse

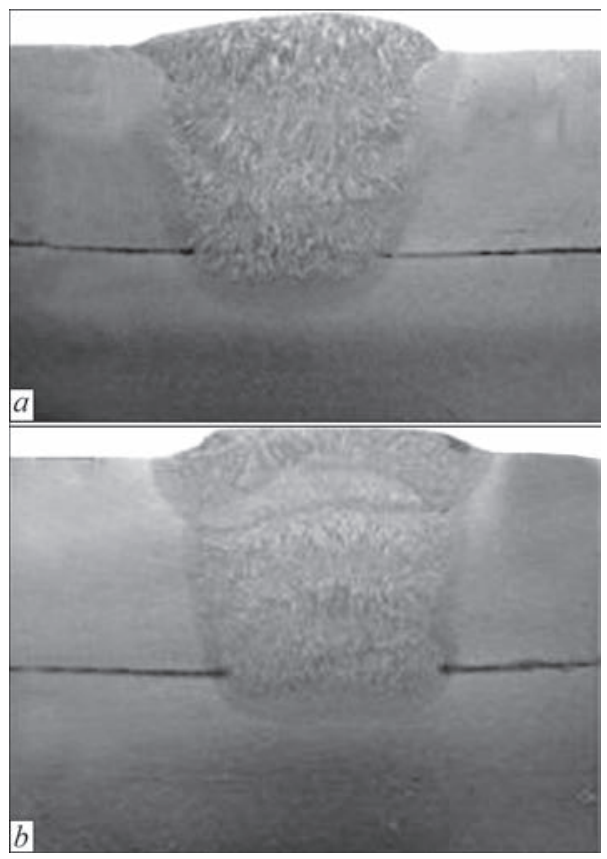

Figure 7. Macrosection of lap-butt joints of strengthening structural elements made with wire DW-A55 (a) and Sv-08G2S (b) 
Table 6. Recommended modes of welding of lap-butt joint with DW-A55 and Sv-08G2S* wire in mixture of $\mathrm{Ar}+18 \% \mathrm{CO}_{2}$

\begin{tabular}{|c|c|c|}
\hline \multirow{2}{*}{ Parameter } & \multicolumn{2}{|c|}{ Groove fill pass } \\
\cline { 2 - 3 } & Filling & $(7.4-8.0) /(3.7-3.8)$ \\
\hline Wire feed rate, $\mathrm{m} / \mathrm{min}$ & $(8.0-9.1) /(4.0-4.1)$ & $(180-200) /(125-130)$ \\
\hline Welding current, A & $(190-220) /(135-140)$ & $(26.0-26.5) /(18.0-18.5)$ \\
\hline Arc voltage, $\mathrm{C}$ & $(26.5-27.0) /(19.5-20.5)$ & $(10-16) /(10-16)$ \\
\hline Wire extension. mm & $(12-23) /(12-23)$ & \\
\hline
\end{tabular}

oscillations for providing smooth transfer to the base metal. Table 5 provides for modes of welding.

Technology of multilayer circumferential lap-butt joints provides for implementation of vertical upward welding process by sectors. All the layers are to be performed using «one layer per two passes» method at width of groove $l \geq 15 \mathrm{~mm}$ (see Figure 2,c). This allows refinement of metal structure and additional increase of values of weld impact toughness. At $l>$ $>15 \mathrm{~mm}$ the first layer is performed using «one layer per one pass», and starting from the second «one layer per two passes» method is applied (Figure $7, a, b$ ). Facing layer of the lap-butt joint should be made by «layer per pass» or «layer per two passes» depending on $l$ value. Total number of layers in lap-butt joints is determined by wall thickness of reinforcing structural elements.

Overhead welding should be carried out with backward electrode position in order to guarantee fusion of edges with pipeline. Modes of welding are given in Table 6 .

The equipment for mechanized gas-shielded arc welding should include professional power sources, which are designed for heavy work. The apparatuses should have protection class not less than IP23. The kitting should contain water-cooled four-rolls external feeding devices, which allow wire feed in the hoses of $6 \mathrm{~m}$ length. All the requirements to equipment, materials and shielding gases are stated in the developed technical documents.

In the conclusion it can be noted that application of mechanized gas-shielded arc welding using traditional (Sv-08G2S) and modern welding consumables (DW-A55 and E7IT-1) allow meeting the requirements made to service characteristics of repaired MGP sections. The result of carried work became development of reference documents on mechanized gas-shielded arc welding for MGP repair, agreed with Company «Urktransgaz».

The results of laboratory-research tests allowed making a decision on industrial approbation of the developed technology at «Ukrtransgaz» enterprises for the purpose of its application in MGP repair under field conditions.

1. GOST 2246-70: Steel welding wire. Specifications. Introd. 01.01.1973. Moscow: Standartinform.

2. AWS A5.18: Carbon steel electrodes and rods for gas shielded arc welding. Miami: AWS.

3. AWS A5.28: Specification for low-alloy electrodes and rods for gas shielded arc welding. Ibid.

4. GOST 26271-84: Flux-cored wire for arc welding of carbon and low-alloy steels. General specifications. Introd. 01.01.1987. Moscow: Gosstandart SSSR

5. AWS A5.36: Specification for carbon and low-alloy steel flux cored electrodes for flux cored arc welding and metal cored electrodes for gas metal arc welding. Miami: AWS.

6. Pidgaetsky, V.V. (1970) Pores, inclusions and cracks in welds. Kyiv: Tekhnika.

7. Pokhodnya, I.K., Yavdoshchin, I.R., Paltsevich, A.P. et al. (2004) Metallurgy of arc welding. Interaction of metals with gases. Kiev: Naukova Dumka.

8. Novozhilov, N.M. (1979) Principles of metallurgy of gas arc welding. Moscow: Mashinostroenie.

9. Pokhodnya, I.K., Suptel, A.M., Shlepakov, V.N. (1972) Fluxcored wire welding. Kiev: Naukova Dumka.

10. STO Gazprom 2-2.2-136-2007: Instruction on welding technologies in construction and repair of industrial and main gas pipelines. Pt 1: Welding technology in repair of industrial and main gas pipelines being in service. Introd. 22.09.2007.

11. ESAB Reference book on welding: All position flux-cored wires for non-alloy and low-alloy steels.

12. Makarov, E.L. (1981) Cold cracks in welding of alloy steels. Moscow: Mashinostroenie.

13. Makhnenko, V.I. (2006) Safety service life of welded joints and assemblies of modern structures. Kiev: Naukova Dumka.

14. GBN V.3.1-00013741-12:2011: Main pipelines. Repair by arc welding in service conditions. Valid from 06.09.2011. Kyiv: Ministry of Energy and Coal Industry of Ukraine.

15. (1967) Testing of metals: Transact. Moscow: Metallurgiya.

16. But, V.S., Maksimov, S.Yu., Olejnik, O.I. (2014) Cracking susceptibility of welded joints in repair structures on main gas pipelines. The Paton Welding J., 11, 15-23.

17. Bekker, M.V., But, V.S., Govdyak, R.M. et al. (2008) Repair of main pipelines under pressure. Kyiv: Kyj.

18. Nikolaev, G.A., Kurkin, S.A., Vinokurov, V.A. (1982) Welded structures. Strength of welded joints and deformation of structures. Moscow: Vysshaya Shkola.

19. GOST 23338-91: Welding of metals. Methods for analysis of diffusion hydrogen content in deposited and weld metal. Introd. 01.07.1992. Moscow: Gosstandart SSSR. 